\title{
Robot Manipulator Pelontar Bola Pingpong Berbasis App Inventor Dan Bluetooth
}

\author{
Andi Hasad'; Ali Musaffa²; Abdul Hafid Paronda³ Muhammad Amin Bakri ${ }^{4}$ \\ 1, 2, 3, 4 Teknik Elektro Universitas Islam “45” Bekasi \\ 1 andihasad@gmail.com
}

\begin{abstract}
Ping pong ball throwers are used as automatic ball shooters as a method of self-training and training the skills of professional athletes. By adding wireless communication, ping pong ball throwers can be controlled remotely. The controller interface is created using the App Inventor so that controllers can be carried out via smart phones. To get the ball throwing "service" required a combination of parameter values of the speed of the ejection motor and the angle of the servo motor.
\end{abstract}

Keyword: Robot, Pingpong Thrower, App Inventor, Bluetooth

\begin{abstract}
ABSTRAK
Pelontar bola pingpong digunakan sebagai penembak bola otomatis sebagai metode berlatih mandiri dan melatih skill atlet profesional. Dengan menambahkan komunikasi nirkabel, pelontar bola pingpong dapat dikendalikan dari jarak yang jauh. Antarmuka pengendali dibuat menggunakan App Inventor agar pengendali bisa dilakukan melalui ponsel pintar. Untuk mendapatkan lemparan bola service dibutuhkan kombinasi nilai parameter dari kecepatan motor pelontar dan sudut dari motor servo.
\end{abstract}

Kata Kunci: Robot, Pelontar Pingpong, App Inventor, Bluetooth 


\section{Pendahuluan}

Mesin pelontar bola pingpong adalah suatu alat yang digunakan untuk melontarkan bola dan membantu permainan tenis meja atau pingpong[1]. Sistem akan menggunakan antarmuka yang dirancang melalui App Inventor lalu di install pada smartphone. App inventor merupakan aplikasi web open-source yang memungkinkan pengguna menciptakan antarmuka aplikasi bagi sistem Android[4]. Karena pengendalian dilakukan melalui smartphone, maka dibutuhkan sistem komunikasi yang mampu melakukan pertukaran data yaitu Bluetooth[10]. HC-05 adalah modul bluetooth yang dipilih karena harganya yang relatif murah[10]. Pengaturan kecepatan pada motor juga dilakukan menggunakan Pulse Width Modulation (PWM) karena hal tersebut lebih baik daripada pemberian tegangan secara kontinyu[9].

\section{Perancangan Sistem}

\subsection{Sistem Mekanik}

Robot ini dirancang menyerupai lengan robot yang memiliki 2 degree of freedom (DoF). Degree of Freedom atau derajat kebebasan adalah jumlah arah yang independen dimana aktuator sebuah robot dapat berputar[9]. Robot akan mampu bergerak ke kiri dan kanan, serta dapat mengubah sudut lontaran bola pingpong secara naik dan turun.

Gambar 1. Rancangan mekanik keseluruhan

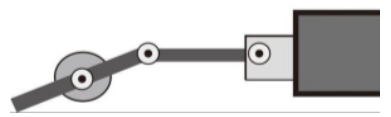

Gambar 2. Ball feeder

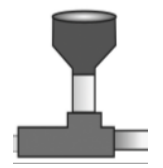

Gambar 3. Penampung bola pingpong

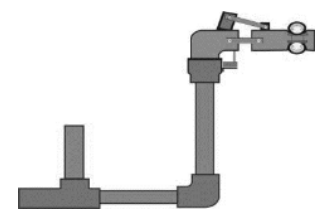

Gambar 4. Pipa distribusi

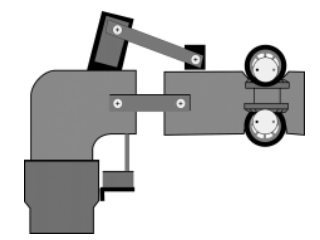

Gambar 5. Kepala pelontar bola pingpong 


\section{JURNAL ILMIAH SUTET}

Vol. 10, No. 1, Juni 2020, P-ISSN 2356-1505, E-ISSN 2656-9175

https://doi.org/10.33322/sutet.v10i1.1281

\subsection{Sistem Elektrik}

Komponen yang dirancang untuk penelitian ini adalah power supply, 2 unit pelontar, 2 unit motor servo, 1 unit motor untuk ball feeder, Arduino UNO dan modul bluetooth HC-05. Modul bluetooth tersebut dipilih karena memiliki harga yang relatif murah[10].

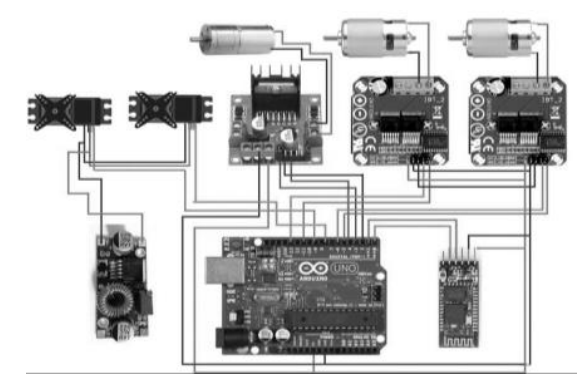

Gambar 6. Diagram pengkabelan sistem elektronik

\subsection{Pengendali}

Robot pelontar bola pingpong akan dikendalikan menggunakan antarmuka grafis yang berisi 4 menu yaitu Beranda, Main, Panduan, dan Keluar. Antarmuka dirancang menggunakan App Inventor. Setelah selesai package instalasi diinstall pada ponsel Android.

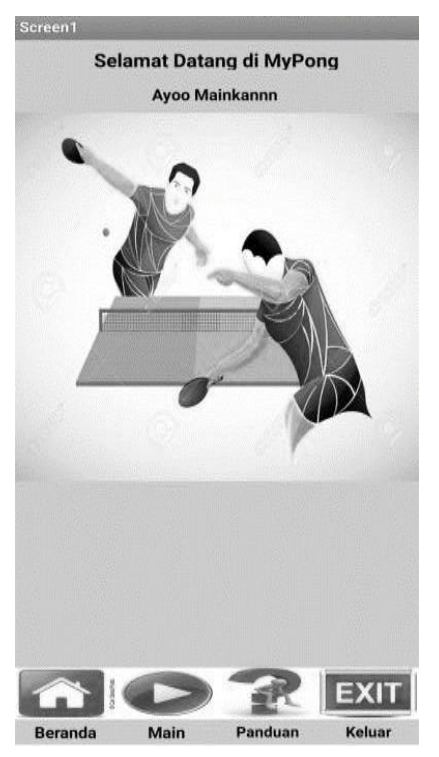

Gambar 7. Perancangan antarmuka pengendali

Pengendali memiliki 3 screen yaitu beranda, main dan panduan. Screen beranda menampilkan halaman utama. Sedangkan screen main akan menampilkan "Cari Perangkat" untuk menghubungkan perangkat dengan robot dan opsi pengaturan pada robot berupa tombol-tombol. 


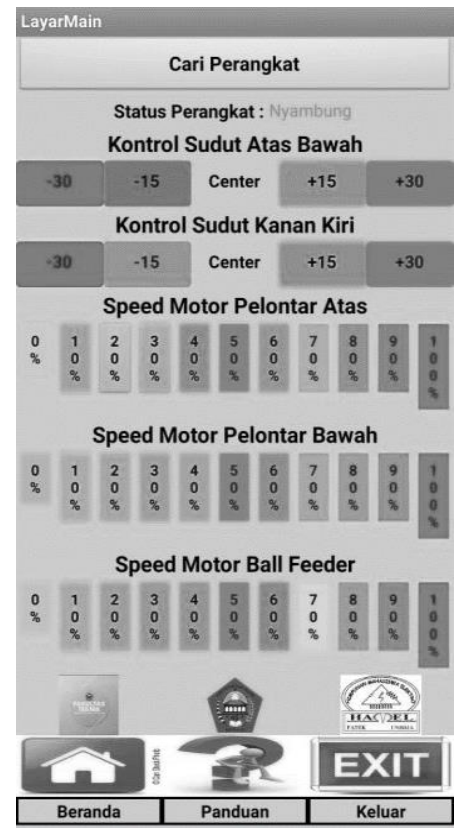

Gambar 8. Tampilan screen Main

Sedangkan pada screen Panduan berisi tentang panduan bagaimana menggunakan antarmuka aplikasi dengan robot pelontar bola pingpong.

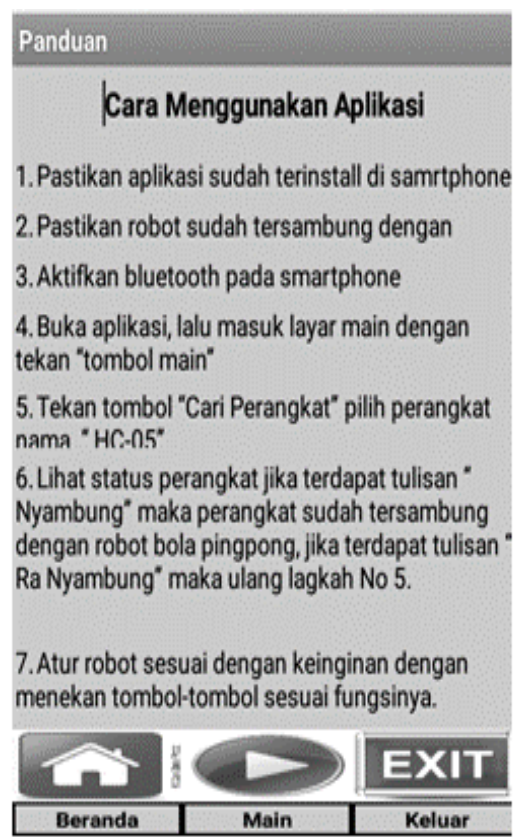

Gambar 9. Tampilan screen Panduan

\section{Pengujian}

\subsection{PWM}

Pengujian Pulse Width Modulation dilakukan dengan cara mengubah nilai PWM dan mengukur nilai tegangan driver L298N. 
Vol. 10, No. 1, Juni 2020, P-ISSN 2356-1505, E-ISSN 2656-9175

https://doi.org/10.33322/sutet.v10i1.1281

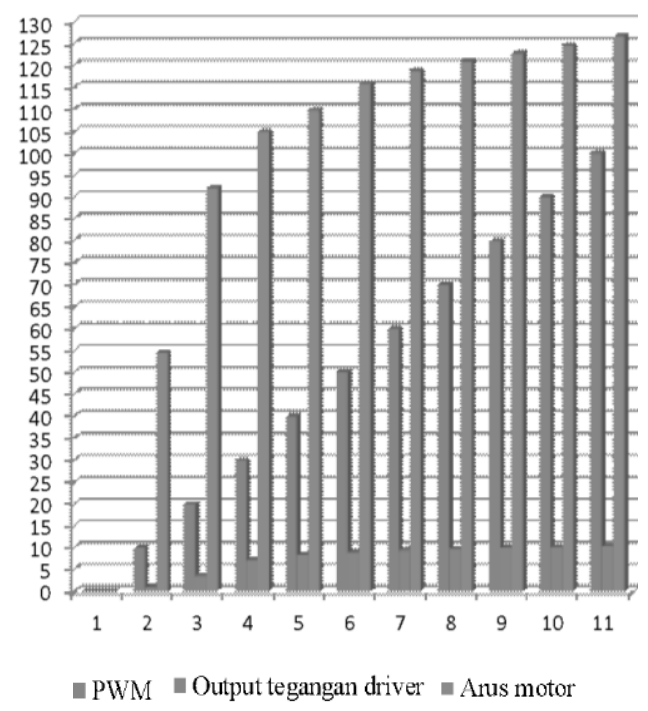

Gambar 10. Grafik nilai PWM dan tegangan

Pada grafik terlihat bahwa bertambahnya nilai PWM menyebabkan naiknya nilai tegangan L298N dan arus pada motor ball feeder. Semakin besar nilai PWM akan semakin besar nilai duty cycle $e^{5}$ sehingga tegangan pun meningkat.

Pengaturan kecepatan motor DC menggunakan Pulse Width Modulation lebih baik daripada pemberian tegangan secara kontiny ${ }^{9}$.

\subsection{Pengiriman Data}

Pengujian ini menggunakan Serial Monitor pada Arduino IDE untuk mengetahui apakah data yang dikirim dari HC-05 ke Arduino sesuai atau tidak.

\begin{tabular}{ccc}
\hline \multirow{2}{*}{ NO } & \multicolumn{3}{c}{ Data Servo Atas Bawah } \\
& Dikirm & Diterima \\
\hline 1 & $\mathrm{a}$ & $\mathrm{a}$ \\
2 & $\mathrm{~b}$ & $\mathrm{~b}$ \\
3 & $\mathrm{c}$ & $\mathrm{c}$ \\
4 & $\mathrm{~d}$ & $\mathrm{~d}$ \\
5 & $\mathrm{e}$ & $\mathrm{e}$ \\
\hline
\end{tabular}

Gambar 11. Komunikasi data servo atas-bawah

\begin{tabular}{ccc}
\hline \multirow{2}{*}{ NO } & \multicolumn{3}{c}{ Data Servo Kanan Kiri } \\
& Dikirm & Diterima \\
\hline 1 & $\mathrm{~g}$ & $\mathrm{~g}$ \\
2 & $\mathrm{~h}$ & $\mathrm{~h}$ \\
3 & $\mathrm{i}$ & $\mathrm{i}$ \\
4 & $\mathrm{j}$ & $\mathrm{j}$ \\
5 & $\mathrm{k}$ & $\mathrm{k}$ \\
\hline
\end{tabular}

Gambar 12. Komunikasi data servo kanan-kiri 


\begin{tabular}{ccc}
\hline \multirow{2}{*}{ NO } & $\begin{array}{c}\text { Data motor pelontar atas } \\
\text { Dikirm }\end{array}$ & Diterima \\
\hline 1 & 0 & 0 \\
2 & 1 & 1 \\
3 & 2 & 2 \\
4 & 3 & 3 \\
5 & 4 & 4 \\
6 & 5 & 5 \\
7 & 6 & 6 \\
8 & 7 & 7 \\
9 & 8 & 8 \\
10 & 9 & 9 \\
11 & 10 & 10 \\
\hline
\end{tabular}

Gambar 13. Komunikasi data pelontar atas

\begin{tabular}{|c|c|c|}
\hline \multirow{2}{*}{$\mathrm{NO}$} & \multicolumn{2}{|c|}{ Data motor pelontar bawah } \\
\hline & Dikirm & Diterima \\
\hline 1 & A & $\mathrm{A}$ \\
\hline 2 & B & B \\
\hline 3 & $\mathrm{C}$ & $\mathrm{C}$ \\
\hline 4 & $\mathrm{D}$ & $\mathrm{D}$ \\
\hline 5 & $\mathrm{E}$ & $\mathrm{E}$ \\
\hline 6 & $\mathrm{~F}$ & $\mathrm{~F}$ \\
\hline 7 & G & G \\
\hline 8 & $\mathrm{H}$ & $\mathrm{H}$ \\
\hline 9 & I & I \\
\hline 10 & $\mathrm{~J}$ & $\mathrm{~J}$ \\
\hline 11 & $\mathrm{~K}$ & $\mathrm{~K}$ \\
\hline
\end{tabular}

Gambar 14. Komunikasi data pelontar bawah

\begin{tabular}{|c|c|c|}
\hline \multirow{2}{*}{$\mathrm{NO}$} & \multicolumn{2}{|c|}{ Data mootor Ball feeder } \\
\hline & Dikirm & Diterima \\
\hline 1 & $\mathrm{~m}$ & $\mathrm{~m}$ \\
\hline 2 & $\mathrm{n}$ & $\mathrm{n}$ \\
\hline 3 & o & o \\
\hline 4 & $\mathrm{p}$ & $\mathrm{p}$ \\
\hline 5 & $q$ & $q$ \\
\hline 6 & $\mathrm{r}$ & $\mathrm{r}$ \\
\hline 7 & $\mathrm{~s}$ & $\mathrm{~s}$ \\
\hline 8 & $\mathrm{t}$ & $\mathrm{t}$ \\
\hline 9 & $\mathrm{u}$ & $\mathrm{u}$ \\
\hline 10 & $\mathrm{v}$ & $\mathrm{v}$ \\
\hline 11 & $\mathrm{w}$ & $\mathrm{w}$ \\
\hline
\end{tabular}

Gambar 15. Komunikasi data ball-feeder

\subsection{Jarak dan Sudut Komunikasi}

Pengujian jarak dan sudut komunikasi dilakukan dengan mengaktifkan bluetooth pada ponsel lalu dihubungkan dengan bluetooth pada robot pelontar pingpong. Selanjutnya ponsel dijauhkan lalu diukur jaraknya serta diuji apakah kedua bluetooth masih dapat berkomunikasi saat melakukan percobaan.

Pengujian pertama dilakukan dengan mencoba komunikasi dari arah sudut $0^{\circ}, 90^{\circ}$, $180^{\circ}, 270^{\circ}$ terhadap bluetooth robot pelontar. Hasil pengujian ini membuktikan bahwa komunikasi bluetooth tetap bisa dilakukan meski dari sudut yang berbeda-beda.

Pengujian kedua dilakukan tanpa penghalang. Masing-masing pengujian yang dilakukan sebanyak 3 kali. Hasil dari pengujian ini menyatakan komunikasi antar bluetooth memburuk pada jarak 21 meter tanpa penghalang. 
Vol. 10, No. 1, Juni 2020, P-ISSN 2356-1505, E-ISSN 2656-9175

https://doi.org/10.33322/sutet.v10i1.1281

Pengujian ketiga dilakukan dengan menambahkan penghalang. Tiap jarak diuji dengan 3 kali percobaan. Hasil dari pengujian ini menyatakan komunikasi antar bluetooth akan memburuk pada jarak 12 meter dengan halangan

Terdapat perbedaan antara studi literatur dengan hasil pengujian yang dilakukan. Pada studi literatur konektivitas bluetooth maksimal $<10$ meter, sedangkan pada pengujian didapatkan 20 meter tanpa penghalang. Komunikasi bluetooth tidak dipengaruhi oleh sudut ${ }^{7}$.

\subsection{Bluetooth}

Berdasarkan datasheet modul bluetooth $\mathrm{HC}-05^{3}$, komponen ini menggunakan versi bluetooth 2.0+ Enhanced Data Rate (EDR). Sedangkan bluetooth pada ponsel yang digunakan adalah versi 5.0 yang memiliki kecepatan transmisi data sekitar $2 \mathrm{Mbps}^{6}$. Namun kelebihan dari bluetooth versi 5.0 tidak bisa didapatkan karena tidak terkoneksi dengan versi bluetooth yang tidak sama atau bisa disebut peripheral compatibility.

\subsection{Perilaku Robot}

Pengujian dilakukan dengan memilih opsi pengaturan aktuator dan ditinjau lemparan bola pingpong yang dihasilkan.

Tabel 1. Nilai parameter robot untuk melakukan perilaku gerak service

\begin{tabular}{|c|c|c|c|c|}
\hline \multicolumn{3}{|c|}{$\begin{array}{c}\text { Kecepatan Motor } \\
\text { Pelontar (\%) }\end{array}$} & \multicolumn{2}{c|}{$\begin{array}{c}\text { Servo } \\
\left({ }^{\circ}\right.\end{array}$} \\
\hline Atas & Bawah & $\begin{array}{c}\text { Ball } \\
\text { feeder }\end{array}$ & $\begin{array}{c}\text { Atas } \\
\text { bawah }\end{array}$ & $\begin{array}{c}\text { Kanan } \\
\text { kiri }\end{array}$ \\
\hline 0 & 0 & 0 & -30 & -30 \\
\hline 10 & 10 & 10 & -15 & 15 \\
\hline 20 & 20 & 20 & 0 & 0 \\
\hline 30 & 30 & 30 & 15 & 15 \\
\hline 40 & 40 & 40 & 30 & 30 \\
\hline 50 & 50 & 50 & & \\
\hline 60 & 60 & 60 & & \\
\hline 70 & 70 & 70 & & \\
\hline 80 & 80 & 80 & & \\
\hline 90 & 90 & 90 & & \\
\hline 100 & 100 & 100 & & \\
\hline
\end{tabular}


Berdasarkan data hasil pengujian perilaku robot diperoleh untuk menghasilkan melakukan gerakan service maka komposisi nilai input pada parameter yaitu:

- Kecepatan pelontar atas-bawah sebesar 30\%

- Kecepatan motor ball-feeder dari $70 \%$ hingga $100 \%$

- Arah sudut servo atas-bawah dari $-15^{\circ}$ hingga $15^{\circ}$

- Arah sudut servo kanan-kiri dari $-30^{\circ}$ hingga $30^{\circ}$

Diluar kombinasi nilai parameter tersebut maka hasil lemparan bola akan dianggap Not Good (NG) karena tidak mampu menghasilkan lemparan bola service.

\section{Kesimpulan}

Dapat disimpulkan bahwa jangkauan koneksi bluetooth antara ponsel Android dan modul bluetooth robot pelontar berjarak 20 meter tanpa penghalang dan 12 meter dengan halangan. Kinerja bluetooth 5.0 pada ponsel akan maksimal bila terkoneksi dengan bluetooth versi yang sama karena keunggulan fitur bluetooth bersifat peripheral compatibility. Lalu untuk mendapatkan lemparan bola service terdapat kombinasi nilai parameter pada robot.

\section{Saran}

Sedangkan saran yang penulis berikan untuk pengembangan adalah menambahkan level kesulitan pada latihan service bola pingpong. Mengganti motor pelontar dan driver motor ball-feeder dengan kualitas yang lebih baik. Membuat aliran bola pingpong pada ballcollection secara otomatis.

\section{Daftar Pustaka:}

[1] Setiadi Firman, Efendy Hanis, "Kendali Mesin Pelontar Bola Tenis Menggunakan Mikrokontroler", Batam: Teknik Elektro Politeknik Batam.

[2] Kusnaedi Nurlan Syarfiatunnisa, Rahayu Indri Nur, "Pengembangan Teknologi Alat Pelontar Bola Tenis Meja Berbasis Microcontroller', Bandung: Universitas Pendidikan Indonesia.

[3] "HC-05 Bluetooth to Serial Port Module", datasheetspdf.com, 17 Januari 2021, https://datasheetspdf.com/pdf-file/1418730/ITead/HC-05/1

[4] Sari Widya Marti, Hardyanto Hafid, "Implementasi Aplikasi Monitoring Pengendalian Pintu Gerbang Rumah Menggunakan App Inventor Berbasis Android", Fakultas Teknologi Informasi Universitas Kristen Duta Wacana.

[5] Hartono, I.S Rifdian, "Rancang Bangun Pulse Width Modulation (PWM) Sebagai Pengatur Kecepatan Motor DC Berbasis Mikrokontroler Arduino", Teknik Listrik Bandar Udara Politeknik Penerbangan Surabaya.

[6] Zaedally Sherali, Siddiqui Farhan, Baig Zubair, "25 Years of Bluetooth Technology", USA \& Australia.

[7] Eritha N. Fadila, Nurussa'adah, Zainuri Akhmad S.T., M.T., "Implementasi Bluetooth HC-05 untuk Mengurangi Tingkat Kecelakaan Pada Pengendara Sepeda Motor", Universitas Brawijaya, Malang.

[8] Aprimaijon, "Analisis Kinerja Pulse Width Modulation Pada Pengendali Tegangan Motor DC”, Universitas Islam Negeri Sultan Syarif Kasim Riau, Pekanbaru. 


\section{JURNAL ILMIAH SUTET}

Vol. 10, No. 1, Juni 2020, P-ISSN 2356-1505, E-ISSN 2656-9175

https://doi.org/10.33322/sutet.v10i1.1281

[9] Casyar Dina, "Pengaturan Pergerakan Robot Lengan Smart Arm Robotic AX-12A Melalui Pendekatan Geometry Based Kinematic Menggunakan Arduino", Fakultas Teknik Universitas Brawijaya, Malang.

[10] Linarti Lusi, "Aplikasi Bluetooth Pada Pengontrol Alat Elektronik Rumah Tangga Dengan Smartphone Android", Teknik Elektro Politeknik Negeri Sriwijaya, Palembang. 